\title{
RESEARCH
}

Open Access

\section{Robotic and laparoscopic liver surgery for colorectal liver metastases: an experience from a German Academic Center}

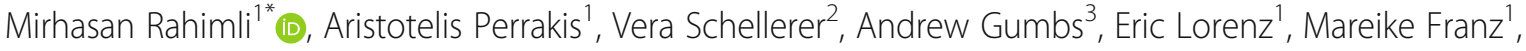
Jörg Arend ${ }^{1}$, Victor-Radu Negrini ${ }^{1}$ and Roland Siegfried Croner $^{1}$

\begin{abstract}
Background: Minimally invasive liver surgery (MILS) in the treatment of colorectal liver metastases (CRLM) is increasing in incidence. The aim of this work was to present our experience by reporting short-term and long-term outcomes after MILS for CRLM with comparative analysis of laparoscopic (LLS) and robotic liver surgery (RLS).

Methods: Twenty-five patients with CRLM, who underwent MILS between May 2012 and March 2020, were selected from our retrospective registry of minimally invasive liver surgery (MD-MILS). Thirteen of these patients underwent LLS and 12 RLS. Short-term and long-term outcomes of both groups were analyzed.

Results: Operating time was significantly longer in the RLS vs. the LLS group (342.0 vs. 200.0 min; $p=0.004$ ). There was no significant difference between the laparoscopic vs. the robotic group regarding length of postoperative stay (8.8 days), measured blood loss (430.4 ml), intraoperative blood transfusion, overall morbidity (20.0\%), and liver surgery related morbidity (4\%). The mean BMI was 27.3 (range from 19.2 to 44.8$) \mathrm{kg} / \mathrm{m}^{2}$. The 30-day mortality was $0 \%$. R0 resection was achieved in all patients (100.0\%) in RLS vs. 10 patients $(76.9 \%)$ in LLS. Major resections were carried out in $32.0 \%$ of the cases, and $84.0 \%$ of the patients showed intra-abdominal adhesions due to previous abdominal surgery. In $24.0 \%$ of cases, the tumor was bilobar, the maximum number of tumors removed was 9 , and the largest tumor was $8.5 \mathrm{~cm}$ in diameter. The 1-, 3- and 5-year overall survival rates were 84, 56.9, and 48.7\%, respectively. The 1- and 3-year overall recurrence-free survival rates were 49.6 and $36.2 \%$, respectively, without significant differences between RLS vs. LLS.

Conclusion: Minimally invasive liver surgery for CRLM is safe and feasible. Minimally invasive resection of multiple lesions and large tumors is also possible. RLS may help to achieve higher rates of RO resections. High BMI, previous abdominal surgery, and bilobar tumors are not a barrier for MILS. Laparoscopic and robotic liver resections for CRLM provide similar long-term results which are comparable to open techniques.
\end{abstract}

Keywords: Robotic surgery, Laparoscopic surgery, Liver resection, Surgical oncology, Colorectal liver metastases, Da Vinci

* Correspondence: mirhasan.rahimli@med.ovgu.de

'Department of General, Visceral, Vascular and Transplant Surgery, University Hospital Magdeburg, Leipziger Str. 44, 39120 Magdeburg, Germany

Full list of author information is available at the end of the article

C C The Author(s). 2021 Open Access This article is licensed under a Creative Commons Attribution 4.0 International License, which permits use, sharing, adaptation, distribution and reproduction in any medium or format, as long as you give appropriate credit to the original author(s) and the source, provide a link to the Creative Commons licence, and indicate if changes were made. The images or other third party material in this article are included in the article's Creative Commons licence, unless indicated otherwise in a credit line to the material. If material is not included in the article's Creative Commons licence and your intended use is not permitted by statutory regulation or exceeds the permitted use, you will need to obtain permission directly from the copyright holder. To view a copy of this licence, visit http://creativecommons.org/licenses/by/4.0/. The Creative Commons Public Domain Dedication waiver (http://creativecommons.org/publicdomain/zero/1.0/) applies to the data made available in this article, unless otherwise stated in a credit line to the data. 


\section{Background}

Liver metastases can be diagnosed in about $40 \%$ of patients with colorectal cancer. Approximately $20 \%$ of patients are diagnosed with synchronous liver metastases at the time of the initial diagnosis [1]. However, this is not a contraindication to surgery, because modern surgery combined with chemotherapy can achieve a 5 -year survival rate up to $60 \%$ [2].

The use of minimally invasive liver surgery (MILS) is increasing worldwide. But currently there is still not enough evidence to determine its value in the treatment of colorectal liver metastases (CRLM). Open liver surgery is still estimated as a standard procedure in the surgical therapy of CRLM. However, CRLM are increasingly being removed via minimally invasive approaches because of the potential benefit to patients [2-4].

A meta-analysis showed that laparoscopic CRLM resection was associated with significantly higher R0 resection rates, less intra-operative blood loss, fewer blood transfusions, less overall morbidity, and shorter length of hospitalization, but with longer operative times when compared to open surgery. There was no significant difference between laparoscopic and open groups regarding the long-term outcomes [2]. In a recent multicenter study, comparable perioperative and long-term oncologic outcomes of robotic and laparoscopic surgery for colorectal liver metastases were identified [4]. Furthermore, another multicenter study figured out a 3-year disease-free and overall survival of 41.9 and $66.1 \%$ in patients who underwent robotic liver surgery for CRLM, respectively. The overall and major morbidity in this study were 27 and 5\%, respectively [5]. These data highlight the value of both minimally invasive techniques, i.e., robotics and laparoscopy in surgery for CRLM.

Even the simultaneous minimally invasive resection of colorectal liver metastases and the primary tumor can be performed safely and effectively [6-8]. A recent meta-analysis showed that simultaneous minimally invasive resection of colorectal cancer and synchronous liver metastases caused significantly lower intra-operative blood loss and blood transfusion, faster recovery of intestinal function and diet, shorter length of stay, and lower rates of surgical complications in comparison to open surgery. In this study, the two procedures did not differ significantly in terms of other perioperative results, disease-free survival, or overall survival [1].

The aim of our study was to present the shortterm and long-term outcomes of our patients after minimally invasive surgery for CRLM with a comparative analysis of laparoscopic and robotic liver resections.

\section{Methods}

\section{Patients}

From the Magdeburg registry of minimally invasive liver surgery (MD-MILS), patients were selected who underwent minor and major minimally invasive liver surgery for CRLM between May 2012 and March 2020. Other types of liver metastases were not considered for this study. Hybrid and hand port-assisted techniques were excluded from the study. We made no selection regarding intrahepatic tumor localization, number of lesions, tumor size, body mass index (BMI), or previous abdominal surgery. The cases requiring vascular reconstruction or multivisceral resection were not selected for minimally invasive liver surgery.

We identified 25 patients in our registry regarding the selection criteria. The patient cohort was divided in two groups. The first group consisted of 13 patients, who underwent laparoscopic liver surgery (LLS), and the second group consisted of 12 patients, who underwent robotic liver surgery (RLS).

\section{Definitions}

The resection of $\geq 3$ segments was defined as a major resection, while the resection of one or two liver segments was considered a minor resection. Overall morbidity was defined as all intraoperative and postoperative complications. Liver surgery related complications included posthepatectomy liver failure, intraoperative and postoperative bleeding, bile leak, bile fistula, bilioma, cholangitis, cholangiosepsis, liver abscess, and portal vein thrombosis. The severity of the complications were assessed according to the Clavien-Dindo classification [9]. As length of stay (LOS), we defined the duration of the postoperative hospital stay. We defined the patient's death within 30 postoperative days as a 30-day mortality. Final diagnosis and number of intrahepatic lesions were evaluated based on histopathological examination.

\section{Minimally invasive liver surgery}

The liver parenchymal dissection during laparoscopic surgery was performed using the water jet or the ultrasonic dissectors. We used the Da Vinci Si System and since September 2019 the Da Vinci Xi system (Intuitive Surgical, Inc., Sunnyvale, CA, USA) for robotic liver surgery. The dissection of liver parenchyma was carried out with the harmonic scalpel, in combination with the bipolar forceps or with monopolar scissors in combination with the Waterjet (ERBEJET ${ }^{\circ}$ 2, Erbe Elektromedizin $\mathrm{GmbH}$, Tübingen, Germany) during robotic liver surgery.

\section{Statistical analysis}

We analyzed patient characteristics, perioperative parameters, type of procedures, and tumor characteristics 
in the entire cohort and between the two groups (LLS vs. RLS).

In addition, we investigated perioperative outcomes of major and minor resections in the entire cohort and as a subgroup analysis in the robotic approach. We also compared minor laparoscopic and robotic liver resections as a subgroup analysis. Furthermore, we analyzed the longterm oncological outcomes after minimally invasive resection of CRLM.

The patient data were collected retrospectively. Data analysis was performed using the IBM SPSS Statistics for Windows, Version 26 (IBM Corp., Armonk, NY, USA). Cross tables were used for the descriptive analysis of categorical variables. We used the number of cases and percentages for data presentation. We applied Fisher's exact test for the significance test for dichotomous variables. The independent samples $t$ test or Mann-Whitney $U$ test were applied for the continuous variables. The data was presented using the mean and standard deviation (SD).

For survival analysis, we used the Kaplan-Meier method to determine overall and recurrence-free survival. The log-rank test was applied to evaluate for any significant differences between the laparoscopic and robotic groups. We used the median survival in months with standard error (SE) and 95\% confidence interval
(CI) to present the survival data. One-, 3-, and 5-year survival rates were given as percentages.

Statistical significance was considered at a $p$ value of $<$ 0.05 .

\section{Results}

Patient characteristics and perioperative outcomes

The patient characteristics and perioperative outcomes of our cohort is summarized in Table 1 . Sixteen male (64.0\%) and nine female $(36.0 \%)$ patients formed our cohort. While the distribution of the sexes was equal in the robotic group, in the laparoscopic group the men predominated with 10 patients $(76.9 \%)$. The patients were 62.8 (SD 11.8) years old on average. The patients in our study were mainly overweight. The mean body mass index (BMI) was 27.3 (SD 5.8) $\mathrm{kg} / \mathrm{m}^{2}$. There was no significant difference between the laparoscopic and the robotic group regarding the sex, age, and BMI. Twenty-one patients (84.0\%) in our study had previously undergone abdominal surgery and were found at the liver resection to have resultant intra-abdominal adhesions. Ten $(76.9 \%)$ of them were in the laparoscopic group and $11(91.7 \%)$ patients in the robotic one. There was no significant difference between the two groups.

The mean operating time was 200.0 (SD 116.8) and 342.0 (101.4) $\mathrm{min}$ in the laparoscopic vs. the robotic

Table 1 Patient demographics and perioperative outcomes in patients with colorectal liver metastasis who underwent minor and major minimally invasive liver surgery (MILS)

\begin{tabular}{|c|c|c|c|c|}
\hline & $\begin{array}{l}\text { LLS } \\
n(\% \text { or } \mathrm{SD})\end{array}$ & $\begin{array}{l}\text { RLS } \\
n \text { (\% or SD) }\end{array}$ & $p$ value & $\begin{array}{l}\text { Total } \\
n(\% \text { or SD) }\end{array}$ \\
\hline$\overline{\text { Total }}$ & $13(52.0)$ & $12(48.0)$ & & $25(100.0)$ \\
\hline \multicolumn{5}{|l|}{ Sex } \\
\hline Male & $10(76.9)$ & $6(50.0)$ & 0.226 & $16(64.0)$ \\
\hline Female & $3(23.1)$ & $6(50.0)$ & & $9(36.0)$ \\
\hline Age (years) & $62.1(12.6)$ & $63.5(11.3)$ & 0.770 & $62.8(11.8)$ \\
\hline $\mathrm{BMI}\left(\mathrm{kg} / \mathrm{m}^{2}\right)$ & $28.3(7.6)$ & $26.2(2.7)$ & 0.894 & $27.3(5.8)$ \\
\hline Operating time ${ }^{a}(\mathrm{~min})$ & $200.0(116.8)$ & $342.0(101.4)$ & 0.004 & $268.2(129.5)$ \\
\hline LOS (days) & $8.5(3.4)$ & $9.3(4.2)$ & 0.852 & $8.8(3.7)$ \\
\hline MBL (ml) & $412.3(529.1)$ & $450.0(278.0)$ & 0.225 & $430.4(419.3)$ \\
\hline Intraoperative blood transfusion & $3(23.1)$ & $2(16.7)$ & 1.000 & $5(20.0)$ \\
\hline Overall morbidity & $2(15.4)$ & $3(25.0)$ & 0.645 & $5(20.0)$ \\
\hline Liver surgery related morbidity & $0(0.0)$ & $1(8.3)$ & 0.480 & $1(4.0)$ \\
\hline Previous abdominal surgery & $10(76.9)$ & $11(91.7)$ & 0.593 & $21(84.0)$ \\
\hline \multicolumn{5}{|l|}{ R status } \\
\hline Ro & $10(76.9)$ & $12(100.0)$ & 0.220 & $22(88.0)$ \\
\hline R1 & $3(23.1)$ & $0(0.0)$ & & $3(12.0)$ \\
\hline Major resections & $3(23.1)$ & $5(41.7)$ & 0.411 & $8(32.0)$ \\
\hline Minor resections & $10(76.9)$ & $7(58.3)$ & & $17(68.0)$ \\
\hline
\end{tabular}

$B M I$ body mass index, MBL measured blood loss, LLS laparoscopic liver surgery, LOS length of postoperative stay, MILS minimally invasive liver surgery, RLS robotic liver surgery, $S D$ standard deviation

${ }^{a}$ The operating time in the robotic group is excluding the docking time 
group, which was significantly different $(p=0.004)$. The mean overall length of postoperative stay and measured blood loss was 8.8 (SD 3.7) days and 430.4 (SD 419.3) $\mathrm{ml}$, respectively, without significant difference between the laparoscopic and the robotic groups. Five patients (20.0\%) received intraoperative blood transfusions. Three (23.1\%) of them were in the laparoscopic group and two $(16.7 \%)$ in the robotic one without a significant difference between the two groups.

We detected five overall complications (20.0\%). Two complications (15.4\%) were in the laparoscopic group. Both of these patients developed a wound infection (Clavien-Dindo grade I). The remaining three complications (25.0\%) were in the robotic group. One patient developed an enterocutaneous fistula from the small intestine postoperatively which did not need surgery (ClavienDindo grade II). The second patient developed a lymphocele, which also did not need operative intervention (Clavien-Dindo grade II). The third complication in the robotic group was a postoperative bile leak after right hemihepatectomy (Clavien-Dindo grade IIIa). This complication was the only liver-specific surgery related complication $(8.3 \%$, overall $4.0 \%)$ in our study. There was no significant difference in overall and liver surgery related morbidity between the laparoscopic and robotic groups.

\section{Type of surgical procedures}

We performed eight major (32.0\%) and 17 (68.0\%) minor minimally invasive liver resections. We recorded three major $(23.1 \%)$ and $10(76.9 \%)$ minor resections in the laparoscopic group. The proportion of major resections was higher in the robotic group with five patients $(41.7 \%)$. Seven robotic minor resections $(58.3 \%)$ were performed in this group. There was no significant difference between the robotic and laparoscopic groups regarding the distribution of minor and major resections (Table 1).

As shown in the Table 2, we performed three left $(12.0 \%)$ and two right $(8.0 \%)$ hemi-hepatectomies in our study. One patient (4.0\%) underwent the anatomical resection of four liver segments and atypical resection of the caudate lobe. The remaining two patients (8.0\%), who underwent major liver resections, underwent resection of three liver segments. Furthermore, we carried out eight left lateral liver resections (32.0\%) and six anatomical segmentectomies (24.0\%). Other minor resections were two bisegmentectomies $(8.0 \%)$ and one anatomical resection of two non-contiguous liver segments (4.0\%).

\section{Tumor characteristics}

In 22 patients $(88.0 \%)$ of our study, we achieved a R0 resection. Three patients (12.0\%) showed a microscopically positive resection margin. All of these patients were in the laparoscopic group. In the robotic group, rate of $\mathrm{R} 0$
Table 2 Surgical procedures in patients with colorectal liver metastasis who underwent minor and major minimally invasive liver surgery (MILS)

\begin{tabular}{llll}
\hline & $\begin{array}{l}\text { LLS } \\
\boldsymbol{n}(\%)\end{array}$ & $\begin{array}{l}\text { RLS } \\
\boldsymbol{n}(\%)\end{array}$ & $\begin{array}{l}\text { Total } \\
\boldsymbol{n}(\%)\end{array}$ \\
\hline $\begin{array}{llll}\text { Major resections } \\
\text { Left hemi-hepatectomy }\end{array}$ & $0(0.0)$ & $3(25.0)$ & $3(12.0)$ \\
Right hemi-hepatectomy & $1(7.7)$ & $1(8.3)$ & $2(8.0)$ \\
Resection of 3 segments & $1(7.7)$ & $1(8.3)$ & $2(8.0)$ \\
Resection > 3 segments & $1(7.7)$ & $0(0.0)$ & $1(4.0)$ \\
Minor resections & & & \\
Left lateral LR & $4(30.8)$ & $4(33.3)$ & $8(32.0)$ \\
Anatomical resection 1 segment & $4(30.8)$ & $2(16.7)$ & $6(24.0)$ \\
Bisegmentectomy & $1(7.7)$ & $1(8.3)$ & $2(8.0)$ \\
Anatomical 2 segment resection & $1(7.7)$ & $0(0.0)$ & $1(4.0)$ \\
Total & $13(100.0)$ & $12(100.0)$ & $25(100.0)$ \\
\hline
\end{tabular}

LLS laparoscopic liver surgery, LR liver resection, MILS minimally invasive liver surgery, $R L S$ robotic liver surgery

resections was $100.0 \%$. But the difference between the two groups was not statistically significant $(p=0.220)$ (Table 1$)$. Twenty patients $(80.0 \%)$ had already been treated with chemotherapy at the time of the operation. The mean value of perioperative carcinoembryonic antigen (CEA) was 112.4 (303.1) $\mathrm{ng} / \mathrm{ml}$ and was higher in the robotic group than in the laparoscopic one. However, this difference was not statistically significant.

As shown in the Table 3, most lesions were located in the left lobe of the liver. We recorded 12 cases (48.0\%) with the tumor localized in the left hepatic lobe. Seven patients $(28.0 \%)$ presented with disease in the right hepatic lobe. In six cases $(24.0 \%)$, the tumor localization was bilobar. The number of liver lesions was confirmed on histopathology. Fourteen patients $(56.0 \%)$ showed a single lesion, six patients (24.0\%) 2 lesions, two patients (8.0\%) 3 lesions, and three patients (12.0\%) had more than 3 lesions. The highest number of liver lesions was 9. Hepatic metastases presented synchronously in 10 cases (40.0\%) and metachronously in 13 cases (52.0\%). The mean longest diameter of the largest lesion was 2.8 (SD 1.9) $\mathrm{mm}$ and 4.2 (SD 1.6) $\mathrm{mm}$ in the laparoscopic and robotic groups, respectively. The largest tumor was $8.5 \mathrm{~cm}$ in longest diameter.

\section{Comparison of minor and major minimally invasive liver resections}

In addition, we performed a comparative analysis of the perioperative outcomes of major and minor resections. Table 4 shows the comparison of preoperative outcomes among minor and major minimally invasive liver resections. The mean operating time was 223.2 (103.8) $\mathrm{min}$ in the minor and 363.6 (132.6) $\mathrm{min}$ in the major MILS group, respectively. This difference was statistically 
Table 3 Tumor characteristics in patients with colorectal liver metastasis who underwent minor and major minimally invasive liver surgery (MILS)

\begin{tabular}{|c|c|c|c|}
\hline & $\begin{array}{l}\text { LLS } \\
n(\% \text { or SD) }\end{array}$ & $\begin{array}{l}\text { RLS } \\
n \text { (\% or SD) }\end{array}$ & $\begin{array}{l}\text { Total } \\
n(\% \text { or SD) }\end{array}$ \\
\hline \multicolumn{4}{|l|}{ Tumor localization } \\
\hline Left hepatic lobe & $6(46.2)$ & $6(50.0)$ & $12(48.0)$ \\
\hline Right hepatic lobe & $3(23.1)$ & $4(33.3)$ & $7(28.0)$ \\
\hline Bilobar & $4(30.8)$ & $2(16.7)$ & $6(24.0)$ \\
\hline \multicolumn{4}{|l|}{ Number of lesions } \\
\hline 1 & $8(61.5)$ & $6(50.0)$ & $14(56.0)$ \\
\hline 2 & $3(23.1)$ & $3(25.0)$ & $6(24.0)$ \\
\hline 3 & $1(7.7)$ & $1(8.3)$ & $2(8.0)$ \\
\hline$>3$ & $1(7.7)$ & $2(16.7)$ & $3(12.0)$ \\
\hline \multicolumn{4}{|l|}{ Time of occurrence } \\
\hline Synchronous & $6(46.2)$ & $4(33.3)$ & $10(40.0)$ \\
\hline Metachronous & $5(38.5)$ & $8(66.7)$ & $13(52.0)$ \\
\hline Missing data & $2(15.4)$ & $0(0.0)$ & $2(8.0)$ \\
\hline Size of tumor $(\mathrm{cm})$ & $2.8(1.9)$ & $4.2(1.6)$ & $3.5(1.8)$ \\
\hline \multicolumn{4}{|c|}{ Preoperative chemotherapy } \\
\hline Yes & $10(76.9)$ & $10(83.3)$ & $20(80.0)$ \\
\hline No & $3(23.1)$ & $1(8.3)$ & $4(16.0)$ \\
\hline Missing data & $0(0.0)$ & $1(8.3)$ & $1(4.0)$ \\
\hline CEA (ng/ml) & $40.1(51.8)$ & $171.5(404.8)$ & $112.4(303.1)$ \\
\hline
\end{tabular}

LLS laparoscopic liver surgery, MILS minimally invasive liver surgery, CEA carcinoembryonic antigen, $R L S$ robotic liver surgery, $S D$ standard deviation

significant $(p=0.008)$. On average, the patients spent 7.6 (SD 3.0) days in the hospital after minor resections and 11.5 (SD 3.9) days after major resections, respectively. This difference was statistically significant $(p=0.007)$. The minor group had significantly $(p=0.013)$ lower mean measured

Table 4 Comparison of minor and major minimally invasive liver resections regarding perioperative outcomes in patients with colorectal liver metastasis

\begin{tabular}{llll}
\hline & $\begin{array}{l}\text { Minor MILS } \\
\boldsymbol{n}(\% \text { or SD) }\end{array}$ & $\begin{array}{l}\text { Major MILS } \\
\boldsymbol{n}(\% \text { or SD) }\end{array}$ & $\boldsymbol{p}$ value \\
\hline Total & $17(68.0)$ & $8(32.0)$ & \\
Operating time ${ }^{\mathrm{a}}$ (min) & $223.2(103.8)$ & $363.6(132.6)$ & $\mathbf{0 . 0 0 8}$ \\
LOS (days) & $7.6(3.0)$ & $11.5(3.9)$ & $\mathbf{0 . 0 0 7}$ \\
MBL (ml) & $274.1(259.5)$ & $762.5(513.2)$ & $\mathbf{0 . 0 1 3}$ \\
Overall morbidity & $3(17.6)$ & $2(25.0)$ & 1.000 \\
Liver surgery related morbidity & $0(0.0)$ & $1(12.5)$ & 0.320 \\
R status & & & \\
$\quad$ R0 & $16(94.1)$ & $6(75.0)$ & 0.231 \\
R1 & $1(5.9)$ & $2(25.0)$ & \\
\hline
\end{tabular}

MBL measured blood loss, LOS length of postoperative stay, MILS minimally invasive liver surgery, $S D$ standard deviation

${ }^{a}$ The operating time in the robotic group is excluding the docking time blood loss $(274.1 \mathrm{ml})$ than the major group $(762.5 \mathrm{ml}) . \mathrm{In}$ terms of overall and liver surgery related morbidity and Rstatus, there was no significant difference between the two groups.

\section{Comparison of minor and major robotic liver resections}

Furthermore, we compared the perioperative outcomes of minor and major robotic liver resections as a subgroup analysis (Table 5). The robotic minor group showed significantly shorter mean operating times $(p=$ $0.035)$ and $\operatorname{LOS}(p=0.010)$ than the robotic major group. There was no significant difference between these subgroups regarding the measured blood loss and overall and liver surgery related morbidity.

\section{Comparison of laparoscopic vs. robotic minor liver resections}

Moreover, we performed a comparative analysis of perioperative outcomes after laparoscopic and robotic minor liver resections (Table 6). Only the operating time was significantly shorter $(p=0.017)$ in the laparoscopic minor group than in the robotic minor group. In terms of the LOS, measured blood loss, morbidity, and R status, we could not detect any significant difference between these subgroups.

\section{Overall and recurrence-free survival}

Finally, we investigated the long-term outcomes of our patients after minimally invasive liver surgery due to the CRLM. The median overall survival was 47 months (SE 22.2, 95\% CI 3.5-90.5). The 1-, 3-, and 5-year overall survival was $84,56.9$, and $48.7 \%$, respectively. The median overall survival in the laparoscopic group was 47 months (SE 18.7, 95\% CI 10.4-83.6) and in the robotic groups 29 months (SE 9.0, 95\% CI 11.4-46.6). There was

Table 5 Comparison of minor and major robotic liver resections regarding perioperative outcomes in patients with colorectal liver metastasis as a subgroup analysis

\begin{tabular}{llll}
\hline & $\begin{array}{l}\text { Minor RLS } \\
\boldsymbol{n}(\% \text { or SD) }\end{array}$ & $\begin{array}{l}\text { Major RLS } \\
\boldsymbol{n}(\% \text { or SD) }\end{array}$ & $\boldsymbol{p}$ value \\
\hline Total & 7 & 5 & \\
Operating time ${ }^{\mathrm{a}}$ (min) & $292.0(83.5)$ & $412.0(85.6)$ & $\mathbf{0 . 0 3 5}$ \\
LOS (days) & $7.0(2.2)$ & $12.4(4.5)$ & $\mathbf{0 . 0 1 0}$ \\
MBL (ml) & $342.9(280.5)$ & $600.0(215.1)$ & 0.117 \\
Overall morbidity & $1(14.3)$ & $2(40.0)$ & 0.523 \\
Liver surgery related morbidity & $0(0.0)$ & $1(20.0)$ & 0.417 \\
R status & & & \\
$\quad$ R0 & $7(100.0)$ & $5(100.0)$ & - \\
R1 & $0(0.0)$ & $0(0.0)$ & \\
\hline
\end{tabular}

$M B L$ measured blood loss, $L O S$ length of postoperative stay, $R L S$ robotic liver surgery, SD standard deviation

${ }^{\mathrm{a}}$ The operating time in the robotic group is excluding the docking time 
Table 6 Comparison of laparoscopic and robotic minor liver resections regarding perioperative outcomes in patients with colorectal liver metastasis as a subgroup analysis

\begin{tabular}{llll}
\hline & $\begin{array}{l}\text { Minor LLS } \\
\boldsymbol{n}(\% \text { or SD) }\end{array}$ & $\begin{array}{l}\text { Minor RLS } \\
\boldsymbol{n}(\% \text { or SD) }\end{array}$ & $\boldsymbol{p}$ value \\
\hline Total & 10 & 7 & \\
Operating time & \\
LOS (days) & $175.1(90.8)$ & $292.0(83.5)$ & $\mathbf{0 . 0 1 7}$ \\
MBL (ml) & $8.0(3.6)$ & $7.0(2.2)$ & 0.669 \\
Overall morbidity & $226.0(247.0)$ & $342.9(280.5)$ & 0.270 \\
Liver surgery related morbidity & $0(0.0)$ & $0(0.0)$ & - \\
R status & & & \\
$\quad$ R0 & $9(90.0)$ & $1(14.3)$ & 1.000 \\
R1 & $1(10.0)$ & $7(100.0)$ & 1.000 \\
\hline
\end{tabular}

MBL measured blood loss, LLS laparoscopic liver surgery, LOS length of postoperative stay, $R L S$ robotic liver surgery, $S D$ standard deviation ${ }^{\mathrm{a}}$ The operating time in the robotic group is excluding the docking time

no significant difference between the groups regarding the overall survival $(p=0.733)$. The 1 - and 3-year overall survival was $70 \%$ vs. $100 \%$ and $60 \%$ vs. $44.4 \%$ in the laparoscopic vs. the robotic group, respectively.

The median overall recurrence-free survival (RFS) was 11 months (SE 7.7, 95\% CI 0-26.2). The 1- and 3-year overall RFS were $49.6 \%$ and $36.2 \%$, respectively. The median overall RFS in the laparoscopic cohort was 24 months (SE 12.2, $95 \%$ CI 0.2-47.8) and in the robotic group 11 months (SE 8.9, 95\% CI 0-28.5), respectively. The groups did not differ significantly in terms of RFS $(p=0.646)$. The 1 - and 3-year overall RFS were 54.9\% vs. $44.4 \%$ and $41.1 \%$ vs. $33.3 \%$ in the laparoscopic vs. the robotic group, respectively.

\section{Discussion}

The utilization of minimally invasive surgery for CRLM is increasing worldwide. The first randomized controlled trial comparing laparoscopic and open liver resection for CRLM was performed by Fretland et al. This study, including 147 open vs. 133 laparoscopic patients, showed that laparoscopic resections were associated with a significantly lower postoperative complication rate and shorter LOS. In terms of blood loss, operating time, resection margins, and 90-day postoperative mortality, there was no significant difference between the open and laparoscopic groups [10]. A recent multicenter study comparing robotic and laparoscopic surgery for colorectal liver metastases demonstrated largely comparable short-term and long-term outcomes after laparoscopic and robotic resections [4].

Our cohort consisted of non-selected cases regarding the patient conditions and tumor characteristics. Only the operating time was significantly longer $(p=0.004)$ in the robotic group when compared to the laparoscopic group in our study. The overall mean operating time was 268.2 (129.5). This finding was comparable with other studies $[4,11]$. There was no significant difference in our study between the laparoscopic and robotic groups regarding the remaining short-term outcomes which is consistent with other studies. Nevertheless, there was a trend towards higher $\mathrm{R} 0$ resections in the robotic group.

Our patients showed a mean BMI value of $27.3 \mathrm{~kg} / \mathrm{m}^{2}$ $\left(\right.$ range $=19.2$ to $\left.44.8 \mathrm{~kg} / \mathrm{m}^{2}\right)$. The highest BMI was 44.8 $\mathrm{kg} / \mathrm{m}^{2}$ in our cohort. Here, we can only corroborate the previous findings that high $\mathrm{BMI}$ is not a contraindication for minimally invasive liver surgery $[12,13]$. The LOS in our study was longer (8.5 days in the laparoscopic and 9.3 days in the robotic group) than the abovementioned studies $[4,10,11]$. One reason for this is that the German DRG (Diagnosis Related Groups) system needs a LOS between 5 and 19 days to get sufficient reimbursement for patient care after liver surgery. The blood loss in our cohort was higher than in other studies $[10,14]$. This can be explained by the high rate of previous abdominal surgery causing adhesions (84.0\%) and major resections $(32.0 \%)$ in our study. Furthermore, we never used a Pringle maneuver during liver surgery in this study.

Overall and liver surgery related morbidity were 20.0 and $4.0 \%$ in our study, respectively. Our complication rates were comparable with the literature. Other studies report an overall complication rate of 19 to $29.6 \%$ after MILS $[4,5,10,11,15,16]$. The mortality rate for MILS is reported in the literature to range from 0 to $0.3 \%$ [4, $5,15,16]$. No patient died in our series. This is an indicator of the safety of minimally invasive liver surgery. $\mathrm{R}$ positive resections were detected in $7 \%$ of cases in open cases and in $6 \%$ in the laparoscopic group in the abovementioned randomized controlled study [10]. The multicenter study published by Beard et al. demonstrated R1 resection rates of 16.7 and $20.0 \%$ in the robotic and laparoscopic groups, respectively. R2 rates of 3.5 and $0.9 \%$ were also shown in the robotic and laparoscopic groups, respectively [4]. Overall in three patients $(12.0 \%)$, we detected a microscopic positive resection margin (R1). All of these patients were in the laparoscopic group. In the robotic group, R0 resections were achieved in all cases $(100.0 \%)$. R2 resections were not noted in our study. Here, we can argue that more precise control of parenchymal dissection during robotic surgery may help to achieve R0 resections more safely.

As can be seen in the other studies and in our work, tumor localization plays no role in the implementation of minimally invasive liver surgery $[4,10]$. Both unilateral (right or left hepatic lobe) and bilobar liver lesions can be approached minimally invasively. Twenty percent of the patients in our study showed multiple liver 
metastases ranging from 3 to 9 lesions. The mean largest tumor size in our study was $3.5 \mathrm{~cm}$ (SD 1.8) with the maximum diameter measuring $8.5 \mathrm{~cm}$. We can thus show that minimally invasive resection of multiple lesions or large tumors can be carried out safely and successfully. In Beard's multicenter study, the tumor size was $\geq 5 \mathrm{~cm}$ in $14.2 \%$ of robotic cases [4].

The comparison of minor and major minimally invasive liver surgery in our work showed that the outcomes regarding the operating time, LOS, and MBL were significantly better in the minor resection group than in the major resection group. It is quite understandable because of the difference in the extent of liver resection. But there was no significant difference between minor and major groups in terms of overall and liver surgery related complications and $\mathrm{R}$ status, which demonstrates the feasibility and safety of the MILS for major liver resections. Moreover, the comparison of minor and major robotic liver resections as subgroup analysis did not show any significant differences between robotic minor and major resection groups regarding the $\mathrm{MBL}$ and morbidity. Because R0 resection was achieved in all robotic patients, there was no difference between these subgroups. Here, we can also say that the implementation of robotics for major liver resections is safe and feasible. Admittedly, the small patient cohort and the retrospective nature are the limitations of our study.

Our overall and recurrence-free survival rates are comparable with previous findings [3-5]. As reported in the multicenter study published by Beard et al., we also did not find any significant difference between laparoscopic and robotic groups regarding long-term outcomes [4]. The meta-analyses showed comparable long-term oncological outcomes after minimally invasive and open resection of CRLM $[1,2]$.

\section{Conclusion}

Minimally invasive liver surgery for CRLM is safe and feasible. Robotic liver surgery may help to achieve higher rates of R0 resections. High BMI, previous abdominal surgery, and bilobar tumor localization are not a barrier for minimally invasive liver surgery. Laparoscopic and robotic liver resections for CRLM provide similar longterm results which are comparable to open techniques.

\section{Abbreviations}

BMI: Body mass index; CEA: Carcinoembryonic antigen; Cl: Confidence interval; MBL: Measured blood loss; LLS: Laparoscopic liver surgery; LOS: Length of postoperative stay; LR: Liver resection; MILS: Minimally invasive liver surgery; RFS: Recurrence free survival; RLS: Robotic liver surgery; SD: Standard deviation; SE: Standard error

\section{Authors' contributions}

MR and RC: conception and design of the study, data analysis and interpretation, writing of manuscript. AP, VS, and AG: conception of the study and interpretation of data. EL, MF, JA, and VN: collection and interpretation of data; grammatical correction. All authors revised the article and approved the submitted version. The authors read and approved the final manuscript.

\section{Funding}

There is no funding for this study. Open Access funding enabled and organized by Projekt DEAL.

\section{Availability of data and materials}

The datasets used and/or analyzed during the current study are available from the corresponding author on reasonable request

\section{Ethics approval and consent to participate}

Our study was submitted to and approved by the Ethics Committee of Otto von Guericke University Magdeburg (Ethik-Kommission der Otto-von-

Guericke-Universität Magdeburg). No problem was seen with conducting the study or using and analyzing the data (reference number: R08-20).

\section{Consent for publication}

Not applicable.

\section{Competing interests}

The authors declare that they have no competing interests or financial ties to disclose.

\section{Author details}

'Department of General, Visceral, Vascular and Transplant Surgery, University Hospital Magdeburg, Leipziger Str. 44, 39120 Magdeburg, Germany.

${ }^{2}$ Department of Pediatric Surgery, University Hospital Erlangen,

Krankenhausstraße 12, 91054 Erlangen, Germany. ${ }^{3}$ Department of Surgery, Centre Hospitalier Intercommunal de Poissy/Saint-Germain-en-Laye, 10 Rue du Champ Gaillard, 78300 Poissy, France.

Received: 4 November 2020 Accepted: 10 December 2020

Published online: 22 December 2020

\section{References}

1. Ye SP, Qiu H, Liao SJ, Ai JH, Shi J. Mini-invasive vs open resection of colorectal cancer and liver metastases: a meta-analysis. World J Gastroenterol. 2019:25(22):2819-32.

2. Xie SM, Xiong JJ, Liu XT, Chen HY, Iglesia-Garcia D, Altaf K, et al. Laparoscopic versus open liver resection for colorectal liver metastases: a comprehensive systematic review and meta-analysis. Sci Rep. 2017;7(1):1012.

3. Guadagni S, Furbetta N, Di Franco G, Palmeri M, Gianardi D, Bianchini M, et al. Robotic-assisted surgery for colorectal liver metastasis: a single-centre experience. J Minim Access Surg. 2020;16(2):160-5.

4. Beard RE, Khan S, Troisi Rl, Montalti R, Vanlander A, Fong Y, et al. Long-term and oncologic outcomes of robotic versus laparoscopic liver resection for metastatic colorectal cancer: a multicenter, propensity score matching analysis. World J Surg. 2020;44(3):887-95.

5. Guerra F, Guadagni S, Pesi B, Furbetta N, Di Franco G, Palmeri M, et al. Outcomes of robotic liver resections for colorectal liver metastases. A multiinstitutional analysis of minimally invasive ultrasound-guided robotic surgery. Surg Oncol. 2019;28:14-8.

6. Dwyer RH, Scheidt MJ, Marshall JS, Tsoraides SS. Safety and efficacy of synchronous robotic surgery for colorectal cancer with liver metastases. J Robot Surg. 2018;12(4):603-6.

7. Croner RS, Rahimli M, Andric M, Stockheim J, Rabczak J, Perrakis A. Robotic left hemihepatectomy with synchronous right hemicolectomy using complete mesocolic excision for advanced metastatic colon carcinoma. Biomed J Sci Tech Res. 2019;20(4):15260-5.

8. Navarro J, Rho SY, Kang I, Choi GH, Min BS. Robotic simultaneous resection for colorectal liver metastasis: feasibility for all types of liver resection. Langenbecks Arch Surg. 2019:404(7):895-908.

9. Bolliger M, Kroehnert JA, Molineus F, Kandioler D, Schindl M, Riss P. Experiences with the standardized classification of surgical complications (Clavien-Dindo) in general surgery patients. Eur Surg. 2018;50(6):256-61. 
10. Fretland AA, Dagenborg VJ, Bjornelv GMW, Kazaryan AM, Kristiansen R, Fagerland MW, et al. Laparoscopic versus open resection for colorectal liver metastases: the OSLO-COMET randomized controlled trial. Ann Surg. 2018; 267(2):199-207.

11. Schiffman SC, Kim KH, Tsung A, Marsh JW, Geller DA. Laparoscopic versus open liver resection for metastatic colorectal cancer: a metaanalysis of 610 patients. Surgery. 2015;157(2):211-22.

12. Uchida H, Iwashita Y, Saga K, Takayama H, Watanabe K, Endo Y, et al. Benefit of laparoscopic liver resection in high body mass index patients. World J Gastroenterol. 2016;22(10):3015-22.

13. Sucandy I, Attili A, Spence J, Bordeau T, Ross S, Rosemurgy A. The impact of body mass index on perioperative outcomes after robotic liver resection. J Robot Surg. 2020;14(1):41-6.

14. Nassour I, Polanco PM. Minimally invasive liver surgery for hepatic colorectal metastases. Curr Colorectal Cancer Rep. 2016;12(2):103-12.

15. Giulianotti PC, Coratti A, Sbrana F, Addeo P, Bianco FM, Buchs NC, et al. Robotic liver surgery: results for 70 resections. Surgery. 2011;149(1):29-39.

16. Zhou Y, Xiao Y, Wu L, Li B, Li H. Laparoscopic liver resection as a safe and efficacious alternative to open resection for colorectal liver metastasis: a meta-analysis. BMC Surg. 2013;13:44.

\section{Publisher's Note}

Springer Nature remains neutral with regard to jurisdictional claims in published maps and institutional affiliations.

Ready to submit your research? Choose BMC and benefit from:

- fast, convenient online submission

- thorough peer review by experienced researchers in your field

- rapid publication on acceptance

- support for research data, including large and complex data types

- gold Open Access which fosters wider collaboration and increased citations

- maximum visibility for your research: over $100 \mathrm{M}$ website views per year

At BMC, research is always in progress.

Learn more biomedcentral.com/submissions 